\title{
Effects of Diffuse Colonization of Grape Berries by Uncinula necator on Bunch Rots, Berry Microflora, and Juice and Wine Quality
}

\author{
David M. Gadoury, Robert C. Seem, Wayne F. Wilcox, Thomas Henick-Kling, \\ Lorenza Conterno, Andrea Day, and Andrea Ficke
}

First, second, and third authors: Department of Plant Pathology, fourth and fifth authors: Department of Food Science and Technology, and sixth and seventh authors: Department of Plant Pathology, Cornell University, New York State Agricultural Experiment Station, Geneva 14456.

Accepted for publication 31 May 2007.

\begin{abstract}
Gadoury, D. M., Seem, R. C., Wilcox, W. F., Henick-Kling, T., Conterno, L., Day, A., and Ficke, A. 2007. Effects of diffuse colonization of grape berries by Uncinula necator on bunch rots, berry microflora, and juice and wine quality. Phytopathology 97:1356-1365.

Production of grape (principally cultivars of Vitis vinifera) for highquality wines requires a high level of suppression of powdery mildew (Uncinula necator syn. Erysiphe necator). Severe infection of either fruit or foliage has well-documented and deleterious effects upon crop and wine quality. We found that berries nearly immune to infection by $U$. necator due to the development of ontogenic resistance may still support diffuse and inconspicuous mildew colonies when inoculated

healthy and free of powdery mildew in late-season vineyard assessments with the naked eye. Nonetheless, presence of these colonies on berries was associated with (i) elevated populations of spoilage microorganisms; (ii) increased evolution of volatile ethyl acetate, acetic acid, and ethanol; (iii) increased infestation by insects known to be attracted to the aforementioned volatiles; (iv) increased rotting by Botrytis cinerea; and (v) increased frequency of perceived defects in wines prepared from fruit supporting diffuse powdery mildew colonies. Prevention of diffuse infection requires extending fungicidal protection until fruit are fully resistant to infection. Despite a perceived lack of improvement in disease control due to the insidious nature of diffuse powdery mildew, potential deleterious effects upon crop and wine quality thereby would be avoided.
\end{abstract} $\approx 3$ weeks post-bloom. Fruit with diffuse mildew colonies appear to be
Production of wine grape, principally cultivars of the European species Vitis vinifera L., requires a high level of suppression of powdery mildew (Uncinula necator, syn. Erysiphe necator). Degradation of crop and wine quality by high levels of powdery mildew on either foliage or fruit has been documented in previous studies $(1,5,7,17,29,31,33)$. Severe foliar infection can debilitate vines, reduce net photosynthesis, and retard ripening and sugar accumulation $(5,17,31)$, all of which can decrease the quality of the affected crop.

Most but not all studies have indicated that very low levels of powdery mildew on fruit can degrade the quality of wine. Inclusion of as little as $3 \%(\mathrm{wt} / \mathrm{wt})$ of severely infected berries yielded perceived defects in red wines prepared from the Vitis interspecific hybrid cv. Rosette (31). Ough and Berg (29) prepared red and white varietal wines from $V$. vinifera 'Thompson Seedless', 'Carignane', or 'Ribier' grape berries with or without "visual mildew infections" and wines prepared from grape berries without visual mildew were ranked as preferable to those prepared from berries bearing visual mildew in 75 to $88 \%$ of samplings by a panel of tasters. Stummer et al. (33) reported compositional and sensory degradation of juice and white wines prepared from $V$. vinifera 'Chardonnay' fruit when $>1$ to $5 \%$ of the bunches were affected by powdery mildew. However, Calonnec et al. (5) reported that powdery mildew had no significant impact on perceived quality of red wines prepared from $V$. vinifera 'Cabernet

Corresponding author: D. M. Gadoury; E-mail address: dmg4@ cornell.edu

* The $\boldsymbol{e}$-Xtra logo stands for "electronic extra" and indicates that the online version contains supplemental material not included in the print edition. Figures 1 and 5 appear in color online.

doi:10.1094/PHYTO-97-10-1356

(C) 2007 The American Phytopathological Society
Sauvignon' until the weight of mildewed fruit exceeded $25 \%$ of the total harvested. An even higher threshold (i.e., $>50 \%$ mildewed fruit, by weight) was reported in this study (5) as the minimum level producing a detectable effect in sensory evaluations of white wines prepared from berries of $V$. vinifera 'Sauvignon Blanc'.

During the course of previous investigations of ontogenic resistance to powdery mildew in grape berries, we found that berries infected just prior to development of immunity supported diffuse, inconspicuous, nonsporulating colonies $(12,13,15)$. These colonies were not noticeable in vineyard assessments of the disease, even when $\geq 30 \%$ of the berries within a cluster were so affected. In subsequent experiments, we noted that fruit supporting diffuse powdery mildew often became severely rotted at harvest due to natural infections by Botrytis cinerea. Our present report is based upon the results of extensive vineyard and winery studies wherein we document the deleterious effects of diffuse powdery mildew on crop and wine quality, and elucidate the possible mechanisms by which this degradation occurs through the agency of $B$. cinerea, fruit-feeding insects, and the epiphytic microflora of diseased berries. Preliminary accounts of this work have been published $(16,18,19)$.

\section{MATERIALS AND METHODS}

Impact of diffuse powdery mildew on bunch rot, insect infestation, evolution of fruit volatiles, and berry microflora. Studies were conducted during the 1999 and 2000 growing seasons in a previously described (15) mixed planting of $V$. vinifera cultivars at Geneva, NY and in a 10-ha commercial vineyard of V. vinifera 'Pinot Noir' at Lodi, NY, during the 1999 to 2002 growing seasons. Two treatments were established in all tests, and were replicated four times in three-vine plots that were located 
randomly within the vineyards. In the first treatment, designated "healthy," powdery mildew and other fungal diseases were controlled rigorously by regular fungicide applications, beginning at $15 \mathrm{~cm}$ of shoot growth and continuing at 7- to 14-day intervals until veraison. In the second treatment, designated "diffuse powdery mildew" (DPM), 30 clusters per replicate were inoculated with a suspension containing $U$. necator at $10^{5}$ conidia $/ \mathrm{ml}$, as described by Gadoury et al. (14), $\approx 3$ weeks after the completion of bloom and midway between two fungicide applications. Our previous research $(12,13,15)$ had shown that berries of multiple $V$. vinifera cultivars become highly resistant, but not immune, to infection and subsequent pathogen development at this stage of crop development.

Bunch rot severity as well as apparent (easily visible) incidence and severity of powdery mildew were assessed at harvest in each year of the study. In addition, the percentage of clusters infested with ants (Formicidae: Leptothorax spp.), picnic beetles (Glischrochilus quadrisignatus), and yellowjackets (Vespula spp.) also was recorded on Pinot Noir clusters at Lodi in 2001 and 2002. Ten clusters per replicate then were picked, brought to the laboratory, and examined at $\times 25$ magnification for evidence of diffuse powdery mildew colonies. Nonsporulating diffuse colonization of grape berries by $U$. necator is rarely visible to the naked eye (15), but can be resolved with a fiber-optic illuminator directed tangentially to the berry surface. Ten berries were picked from each of the sampled clusters and examined as above. The percentage of the berry surface supporting diffuse powdery mildew colonies was estimated visually and recorded. Feeding behavior of the above insects was observed on several occasions at the Lodi site, and upon selected clusters returned to the laboratory in 2001 and 2002.

Among the Pinot Noir clusters harvested at the Geneva and Lodi site in 2000, and at the Lodi site in 2001 and 2002, 10 berries from each of 10 clusters per treatment replication were shaken for $30 \mathrm{~min}$ in a 1-liter Erlenmeyer flask containing $100 \mathrm{ml}$ of an extraction buffer ( $9 \mathrm{~g}$ of $\mathrm{NaCl}, 1 \mathrm{~g}$ of peptone, and $100 \mu \mathrm{l}$ of sodium dodecyl sulfate per liter). Four semiselective agar media in $9-\mathrm{cm}$ petri plates were employed to quantify the berry microflora: (i) malolactic broth agar plus cyclohexamide at $300 \mu \mathrm{g} / \mathrm{ml}$ (MLBC), for growth of lactic acid bacteria (6); (ii) yeast medium agar (YMA), for growth of yeast genera commonly found on grape berries and in wine (2); (iii) yeast medium agar plus cyclohexamide at $300 \mu \mathrm{g} / \mathrm{ml}$ (YMC), for growth of cyclohexamideresistant yeasts, primarily Brettanomyces (3); and (iv) lysine agar (LYS) for growth of selected non-Saccharomyces yeasts, such as Hanseniaspora, Aureobasidium, Metschnikowia, and Candida spp. (34). A 100- $\mu$ l aliquot of the crude extract and 100- $\mu$ l aliquots of $10^{-1}, 10^{-2}$, and $10^{-3}$ dilutions of the crude extract were dispensed into petri plates of each medium and spread on the surface using a glass rod. The plates were incubated at $25^{\circ} \mathrm{C}$ for 6 days, and then the number of colonies was recorded for the dilution that produced at least 50 discrete colonies per plate.

For fruit collected from both sites in 2000, 30 colonies were selected at random from each of three replicate plates of each medium, subcultured, and identified, insofar as possible, based upon their morphology at $\times 400$ to 800 . In general, this allowed only the tentative identification of yeast genera (Saccharomyces, Candida, Metschnikowia, Brettanomyces, Kloeckera, Aureobasidium, and Hanseniospora) and the bacterial genera Acetobacter and Lactobacillus. Additional and more definitive polymerase chain reaction (PCR) and sequencing methods were used to identify yeast genera that were isolated on YMA and LYS from fruit at Lodi in 2001 and 2002. Twenty colonies selected at random from each replicate plate per medium were subcultured and identified. Cultures grown from single cells were suspended in $10 \mathrm{mM}$ Tris- $\mathrm{HCl}$ buffer $(\mathrm{pH} 8)$, and lysate was obtained by boiling the cells in microfuge tubes for $10 \mathrm{~min}$. Cell debris then was removed by centrifugation at $14,000 \times g$ and the supernatant removed to a clean microfuge tube for storage at $4^{\circ} \mathrm{C}$. Primers NL-1 (5'-GCATATCAATAAGCGGAGGAAAAG-3') and NL-4 (5'-GTCCGTGTTTCAAGACGG-3'), specific for a portion of the large subunit (LSU) of the $26 \mathrm{~S}$ rDNA gene of ascomycetous yeasts, were synthesized based on sequences from a previously published method $(25,27)$, and were used in 50- $\mu$ l Hot Start Taq MasterMix (Qiagen, Chatsworth, CA) with reagents at the kitrecommended concentrations. The reaction was performed in a Stratagene Gradient-Plus thermal cycler. PCR reactions were carried out after one cycle of incubation for $15 \mathrm{~min}$ at $95^{\circ} \mathrm{C}$. Amplification of the 26S rDNA fragment was accomplished in 40 cycles of denaturation at $95^{\circ} \mathrm{C}$ for $50 \mathrm{~s}$, annealing at $52^{\circ} \mathrm{C}$ for $50 \mathrm{~s}$, and elongation at $72^{\circ} \mathrm{C}$ for $2 \mathrm{~min}$. A final step of $72^{\circ} \mathrm{C}$ for $10 \mathrm{~min}$ was part of the programs. Amplification products were analyzed via electrophoresis at $100 \mathrm{~V}$ for $60 \mathrm{~min}$ in a $1 \%$ agarose gel stained with ethidium bromide following standard protocols (32). PCR products were then purified and concentrated for sequencing by using the QiaQuick PCR purification kit (Qiagen). Elution from the spin column with 30 to $50 \mu \mathrm{l}$ of water concentrated the amplification product to the appropriate level required for sequencing following the standard methods used by the Cornell University BioResource Center Sequencing Facility. Purified and concentrated PCR product was quantified and mixed with the same primers used for PCR. Approximately $1 \mu \mathrm{g}$ of amplicon $(10 \mu \mathrm{l})$ was mixed with 8 pmol of either forward or reverse primer. Sequencing reactions were carried out at the BioResource Center for Advanced Technology at Cornell University and separated on an Applied Biosystems Automated 3730 DNA Analyzer (ABI, Foster City, CA). Results from both strand sequences were assembled and the resultant sequence analyzed with the DNAStar analysis software package (Lasergene, Madison, WI). DNA consensus sequences of the portion of the LSU of the 26S rDNA gene were submitted to a BLAST search on the National Center for Biotechnology Information website.

Volatiles evolved by berries with and without diffuse powdery mildew. Three replicate samples of five Pinot Noir clusters each were collected from the healthy and DPM treatments at the Lodi site on the commercial harvest date in 2001, 2002, and 2003 and were sealed immediately in 6-liter polyvinylchloride boxes. Volatile ethyl acetate, acetic acid, and ethanol evolved by the clusters were assayed by solid-phase microextraction (SPME) as described by Pawliszyn (30), and by gas chromatography/mass spectroscopy (GCMS). A 2-cm-long three-phase extraction polymer SPME fiber with affinity for low molecular weight volatiles was exposed for $30 \mathrm{~min}$ to extract volatiles from the headspace above the respective grape clusters. The SPME fiber was thermally desorbed at $250^{\circ} \mathrm{C}$ in a splitless injection into an Agilent 6890 gas chromatograph equipped with an Agilent 5973 Mass Selective Detector (Agilent Technologies, Wilmington, DE) and HP-5MS capillary chromatography column (Agilent Technologies). Ion peak areas for the three target analytes were integrated and recorded. Grape clusters were assayed in this manner at 24-h intervals up to $72 \mathrm{~h}$ after harvest.

Impact of fruit-feeding insects on severity of bunch rot on fruit clusters with or without diffuse powdery mildew. Wounds created by fruit-feeding insects are potential infection courts for microorganisms that cause bunch rots. At the Lodi site in 2001 and 2002, a subset of 30 clusters from each replicate of the healthy and DPM treatment was sprayed with the insecticide fenpropathrin (Danitol 2.4 EC; Valent Biosciences Corp., Walnut Creek, CA) at $0.5 \mathrm{~g} /$ liter a.i. at veraison, and twice more at 10-day intervals in order to deter infestation of the clusters by fruitfeeding insects. No other fruit were treated with an insecticide. Incidence of insect infestation and the severity of bunch rot were recorded at harvest in all treatments.

Preparation and evaluation of wines from berries with and without diffuse powdery mildew. Plots consisting of five rows with 100 vines each were replicated three times for both the 

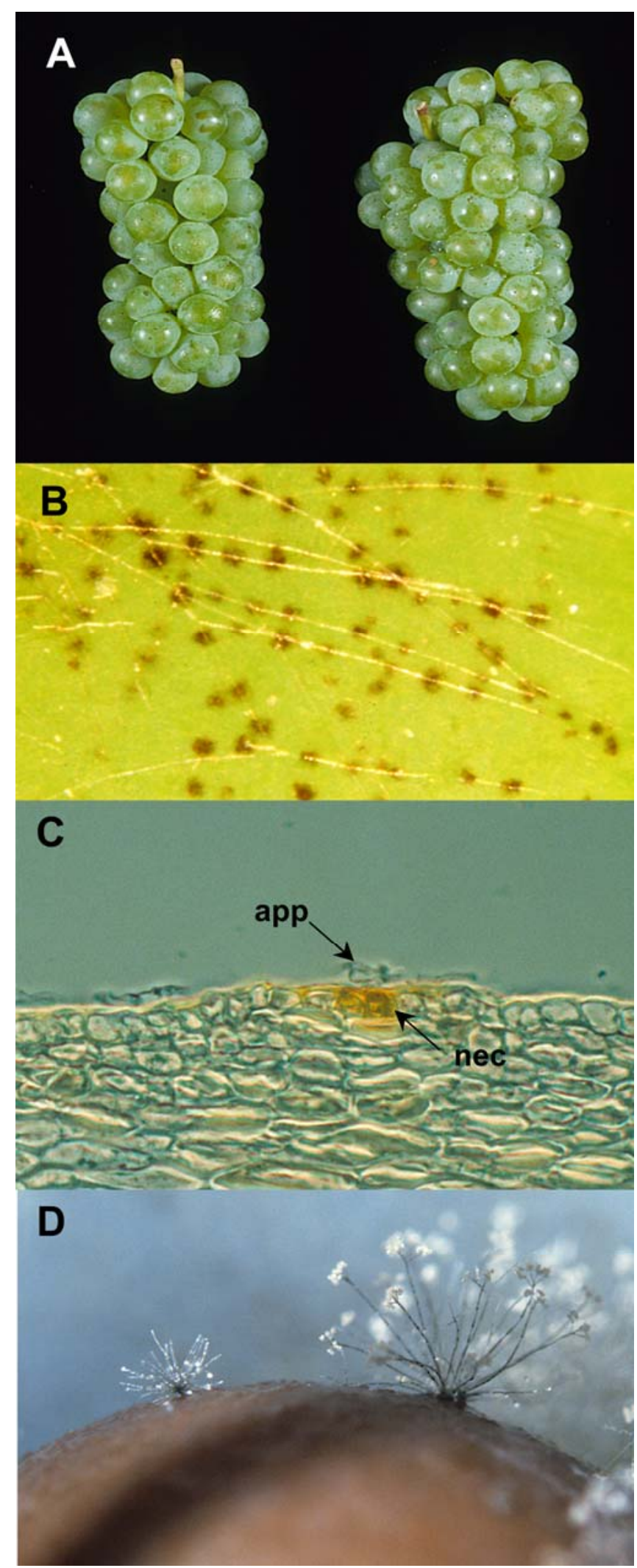

Fig. 1. A, Mildew-free Chardonnay fruit cluster (left) and fruit cluster in which $24 \%$ of the berries support one or more diffuse powdery mildew colonies (right). Macroscopically, both clusters appear free of powdery mildew. B, Nonsporulating hyphae from diffuse powdery mildew colony. C, Cross section of Chardonnay berry epidermis showing necrosis of two epidermal cells (nec) beneath hyphae of diffuse powdery mildew colony. D, Botrytis cinerea emerging from lenticel (left) and calyx end (right) of Chardonnay berry bearing diffuse powdery mildew colonies. healthy and DPM treatments at the Lodi site in 2000, 2001, and 2002 . Vines in the healthy treatment were sprayed rigorously with fungicides per the grower's standard program to control powdery mildew and other fungal diseases. Within the DPM plots, all clusters were inoculated with a suspension of $10^{5}$ conidia of $U$. necator per milliliter on a date midway between two fungicide applications, $\approx 3$ weeks after bloom. Grape berries were harvested at ripeness in each year of the study. Approximately $110 \mathrm{~kg}$ of fruit were harvested from each plot, cooled to $4^{\circ} \mathrm{C}$, and destemmed, and the sugar content measured with a refractometer. Destemmed berries were transferred to 120-liter stainless steel open top drums. To the crushed grape berries, $\mathrm{SO}_{2}$ at $30 \mathrm{mg} / \mathrm{liter}$ and diammonium hydrogen phosphate at $1 \mathrm{~g} / \mathrm{liter}$ was added. A 50-ml juice sample was collected and frozen for later analysis. Grape must was warmed to 25 to $30^{\circ} \mathrm{C}$, then inoculated with a rehydrated yeast starter culture and fermented at $20^{\circ} \mathrm{C}$ on the skins to dryness (residual sugar at $<2 \mathrm{~g} / \mathrm{liter}$ ). The wine was pressed and filled into 20-liter glass carboys fitted with fermentation locks. At the end of alcoholic fermentation, the wine was inoculated with a malolactic starter culture (Lallemand OSU-1) and allowed to complete malolactic fermentation at $20^{\circ} \mathrm{C}$. It then was racked and sulfited $(20 \mu \mathrm{g} / \mathrm{ml})$, racked again if necessary, with free $\mathrm{SO}_{2}$ adjusted to 20 to $30 \mathrm{mg} /$ liter before cold stabilization at $-2^{\circ} \mathrm{C}$ for 2 to 4 weeks. After cold stabilization, the wine was racked again (with free $\mathrm{SO}_{2}$ adjusted to $30 \mathrm{mg} / \mathrm{liter}$ ), bottled into $750-\mathrm{ml}$ bottles with cork closures, and stored at $16^{\circ} \mathrm{C}$ for a minimum of 18 months before sensory evaluation. Juice samples were analyzed for $\mathrm{pH}$, titratable acidity (TA), and total soluble solids ( ${ }^{\circ}$ Brix). Malic, lactic, tartaric, and acetic acid were measured by high-performance liquid chromatography, and color was measured by absorbance at 280, 420, and $520 \mathrm{~nm}$. Wine samples were analyzed for $\mathrm{pH}$, TA, free/total $\mathrm{SO}_{2}$, malic, lactic, tartaric, and acetic acid, residual sugar (glucose + fructose), and color.

Wines were evaluated by a panel of 8 to 11 individuals in a blind test where samples were assigned three-digit codes (26). The wines were served in ISO standard wineglasses at room temperature $\left(22\right.$ to $\left.25^{\circ} \mathrm{C}\right)$ in random order, and each individual rated each replicate twice. Individuals ranked each replicate for intensity of the following standard organoleptic factors on a nonstructured $10-\mathrm{cm}$ line scale (26) denoting intensity of (i) cherry or berry flavor, (ii) pepper or spice, (iii) green or vegetative taste, (iv) mouth feel, and (v) bitterness. In cases where an individual perceived a negative attribute in the taste or aroma of a replicate, this attribute also was described and recorded in tasting notes. To standardize rankings based upon the sensitivity of individuals in scoring the above factors, all rankings for a given factor determined by an individual were scaled to the maximum value applied to that factor by the same individual. For example, if an individual assigned a maximum value of 8.5 across all wines for the factor "bitterness," all other values recorded by that individual for bitterness were standardized as a fraction of 8.5 , and these resultant values were used to compute treatment means and standard errors. Negative attributes that were perceived by an individual in both the first and second sampling of a replicate were compiled and the percentage of individuals on a panel that applied one or more negative attributes to a replicate was recorded.

\section{RESULTS}

Diffuse colonization of grape berries was never visually evident in any vineyard assessment of disease 2 months after inoculation (Fig. 1A). However, examination of the berries at $\times 25$ magnification 3 weeks or more after inoculation revealed a diffuse and nonsporulating network of hyphae (Fig. 1B) that was accompanied by necrotic epidermal cells at the sites of appressorial attachment (Fig. 1C). From 24 to $58 \%$ of the berries in inoculated clusters 
bore some diffuse powdery mildew colonies (Figs. 2 to 4), but the proportion of the berry surface bearing such colonies was relatively low, ranging from $\approx 1$ to $10 \%$ (Figs. 2 to 4 ).

There was a clear association between the presence of diffuse powdery mildew and the severity of bunch rot (Fig. 1D) in all cultivars, locations, and years of the study (Figs. 2 to 4). Uninoculated fruit showed only trace levels of powdery mildew and were relatively unaffected by bunch rot (Fig. 2 to 4 ). In contrast, approximately one-fourth to one-half of the fruit inoculated with $U$. necator 3 weeks post bloom bore diffuse powdery mildew colonies, and bunch rot severity was manyfold greater $(P=0.05)$ on these clusters than on those that were not inoculated (Figs. 2 to 4 ).

Pinot Noir fruit with diffuse powdery mildew also were more heavily infested with ants (Leptothorax spp.), sap beetles (Glischrochilus quadrisignatus), and yellowjackets (Vespula spp.) (Fig. 5A to C) in both 2001 and 2002. Only trace percentages of diffuse powdery mildew occurred in the healthy treatment (Fig. 4; Table 1), and $<3 \%$ of the clusters were infested by one or more of the above insects (Table 1). In comparison, from 27.3 to $34.8 \%$ of the berries from the DPM treatment bore diffuse mildew colonies in 2001 and 2002, respectively (Fig. 4), and the mean level of insect infestation ranged from 38.3 to $49.4 \%$ (Table 1) among clusters not treated with the insecticide fenpropathrin. Both the incidence of insect infestation and severity of bunch rot was significantly $(P=0.05)$ reduced when the insecticide fenpropathrin was applied to DPM clusters (Table 1). DPM clusters treated with fenpropathrin in 2001 were free of fruit-feeding insects when examined near harvest, and the incidence of bunch rot was reduced to $5.9 \%$, compared with $15.9 \%$ in DPM clusters that were not treated with fenpropathrin (Fig. 4A; Table 1). Similar results were obtained in 2002 (Table 1).

Yellowjackets were observed while feeding upon DPM clusters in the vineyard (Fig. 5C and D), and upon clusters returned to the laboratory for microscopic observation (Fig. 5E and F). Feeding wounds usually were inflicted by yellowjackets within $30 \mathrm{~s}$ of being placed on intact fruit. The insect's mandibles produced slits $\approx 0.2 \mathrm{~mm}$ long in the berry epidermis, which then exuded sap from the internal tissue of the berry (Fig. 5F). Prolonged feeding $(>5 \mathrm{~min})$ resulted in multiple wounds of this type and eventual mining of a cavity extending into the internal tissues of the berry (Fig. 5A).

Fruit with DPM produced far more volatiles than healthy fruit when measured within $24 \mathrm{~h}$ after harvest (i.e., 13 to 259 times more volatile ethyl acetate, 4 to 18 times more volatile ethanol, and one to eight orders of magnitude more acetic acid) (Table 2).

Populations of epiphytic fungi and bacteria recorded on four different semiselective media were one to several orders of magnitude higher $(P=0.05)$ on berries with diffuse powdery mildew than on healthy fruit in all years of the study (Fig. 6A to D). The methods employed in 2000 (semiselective media with subsequent identification based on colony characteristics and microscopic examination) revealed no significant $(P=0.05)$ qualitative differences between DPM and healthy fruit in the distribution of the particular classes of epiphytic microbes (as reflected by their numbers on the specific media) as a percentage of total microflora at either Geneva or Lodi (Fig. 6A and B). However, more definitive PCR-based tests used in 2001 and 2002 to better identify the organisms recovered on YMA and LYS media indicated a significant $(P=0.05)$ change from a predominance of Aureobasidium spp. on healthy fruit (65.7 and $67.7 \%$ of total microflora in 2001 and 2002, respectively) to a predominance of Hanseniospora spp. (68.8 and $80.8 \%$, respectively). Metschnikowia sp. and Candida stellata also were detected on DPM berries in both years, but not on healthy fruit (Fig. 7). No significant $(P=0.05)$ differences were detected in either 2001 or 2002 in the comparative percentages of other species of Candida, Sporidiobolus, Cryptococcus, Debaryomyces, Rhodotorula, or Acetobacter isolated from healthy versus DPM fruit (data not shown). The pres-
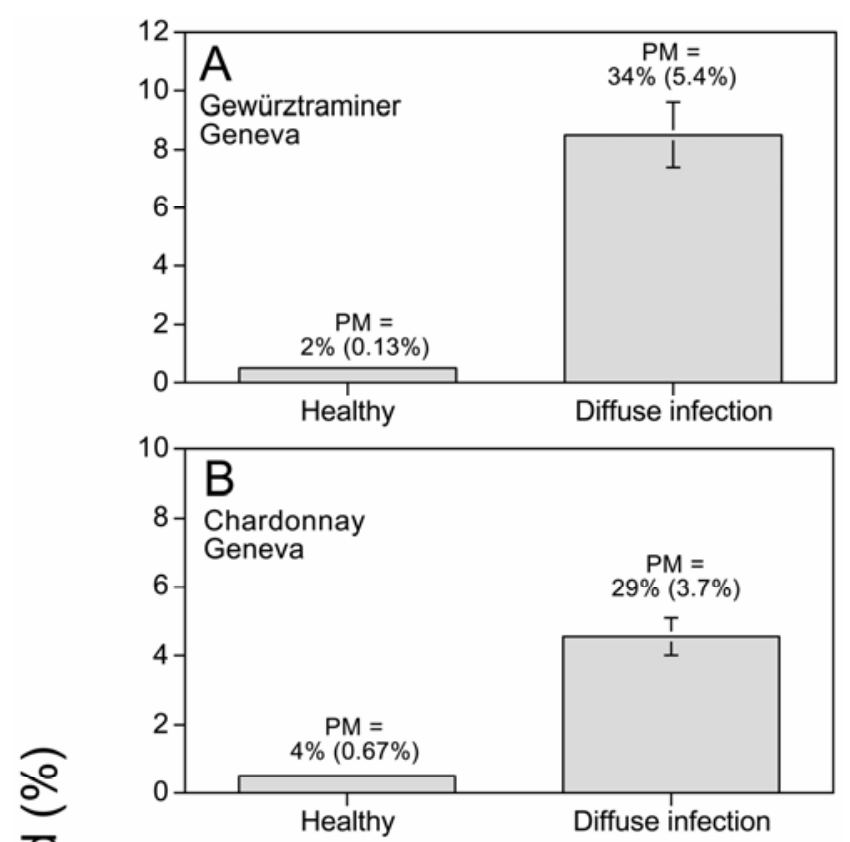

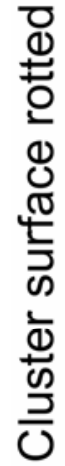
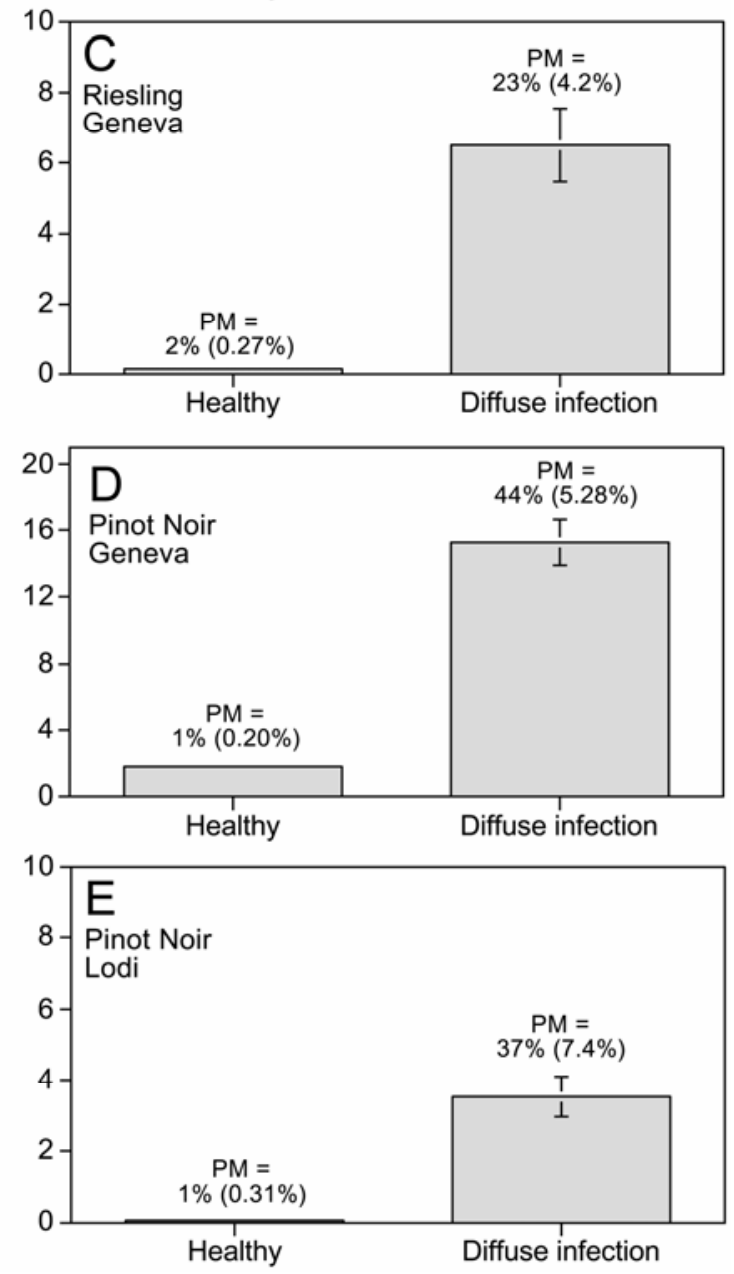

Fig. 2. Effects of diffuse powdery mildew infection of grape berries upon the severity of Botrytis bunch rot at A to D, Geneva or E, Lodi, NY in 1999. Clusters at each location were subjected to the same fungicide spray program. "Healthy" clusters were relatively mildew free. "Diffuse infection" treatment was inoculated with a spore suspension of Uncinula necator midway between two fungicide sprays, just before berries became immune to powdery mildew infection ( $\approx 4$ weeks post bloom). Severity of bunch rot was assessed 1 week preharvest. Numbers above each bar indicate the percentage of berries in clusters with any amount of diffuse powdery mildew, or (in parentheses) the percentage of the berry surface covered by diffuse powdery mildew. Bars indicate one standard error of the mean. 

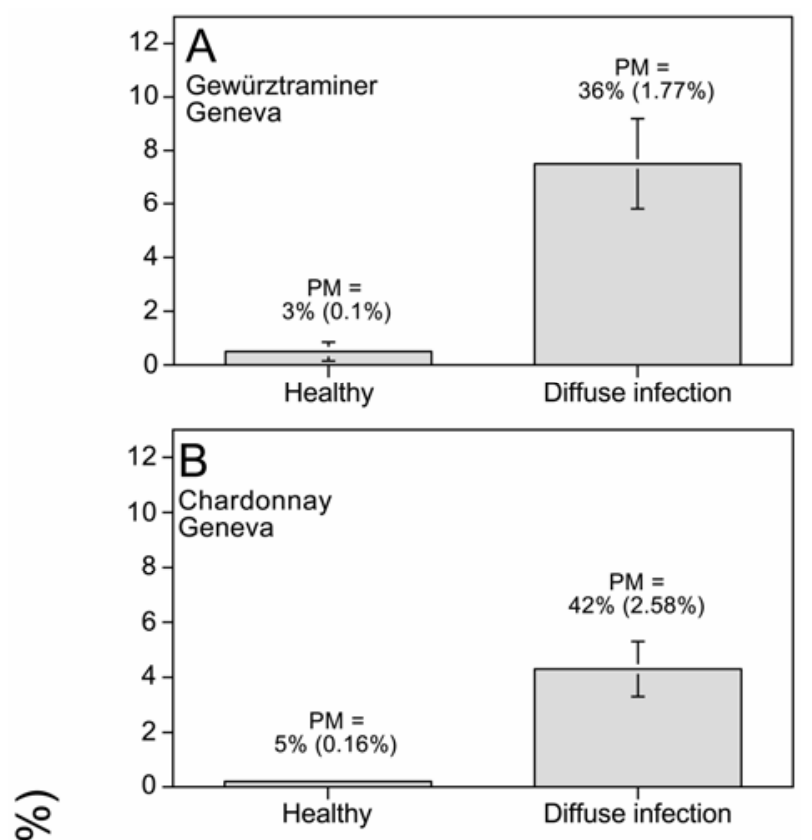

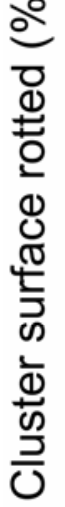
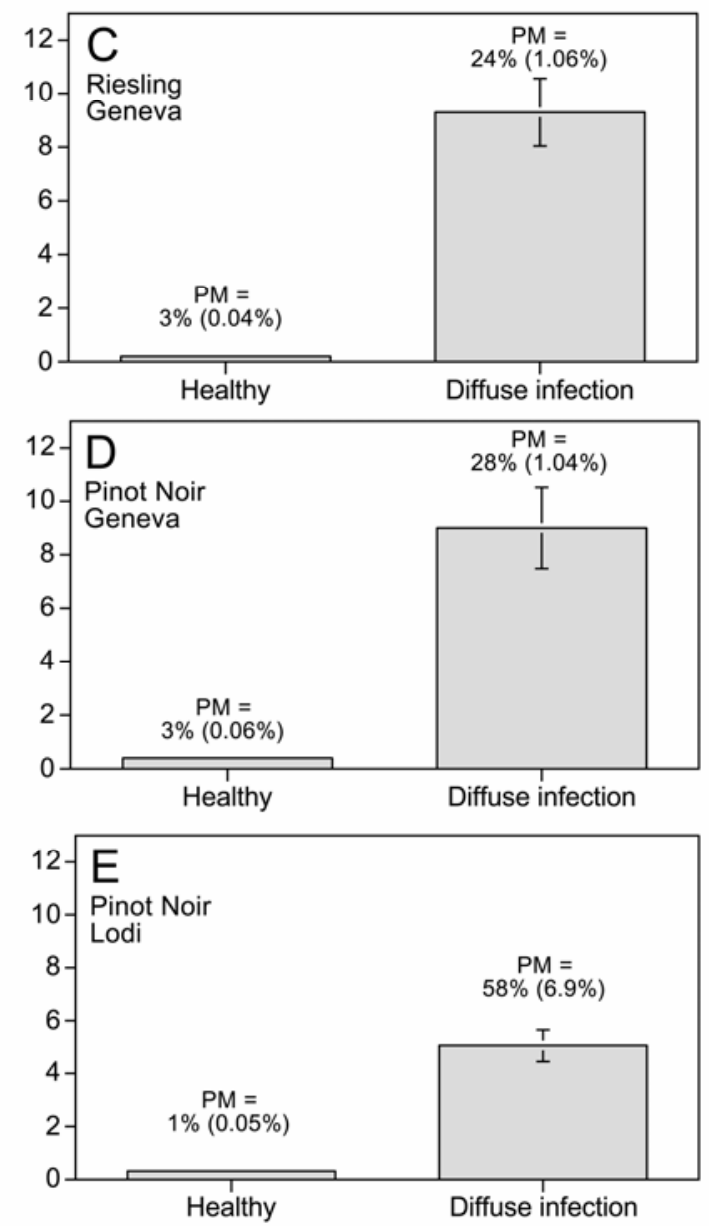

Fig. 3. Effects of diffuse powdery mildew infection of grape berries upon the severity of Botrytis bunch rot at A to D, Geneva or E, Lodi, NY in 2000. All clusters at each location were subjected to the same fungicide program. "Healthy" clusters were relatively mildew free. "Diffuse infection" treatment was inoculated with a spore suspension of Uncinula necator midway between two fungicide sprays, just before berries became immune to powdery mildew infection ( $\approx 4$ weeks post bloom). Severity of bunch rot was assessed at 1 week preharvest. Numbers above each bar indicate the percentage of berries in clusters with any amount of diffuse powdery mildew, or (in parentheses) the percentage of the berry surface covered by diffuse powdery mildew. Bars indicate one standard error of the mean. ence of DPM had no significant $(P=0.05)$ effect, following malolactic fermentation, on soluble solids levels of juice at harvest, or on $\mathrm{pH}$, titratable acids, tartrate, malate, lactate, or acetate levels in wine made from these fruit, in any year of the study (Table 3). Neither were individuals able to detect significant differences $(P=0.05)$, following malolactic fermentation, between wines made from fruit with or without DPM with respect to the intensity of the organoleptic factors "cherry or berry flavor," "pepper or spice," "green or vegetative taste," "mouth feel," or "bitterness" during blind tastings. However, in all years of the study, individuals applied a significantly $(P=0.05)$ higher number of negative descriptors to wines prepared from fruit with DPM than to wines prepared from fruit essentially free of such infections (Fig. 8).

\section{DISCUSSION}

In previous work (12-15), we demonstrated that grape berries acquire substantial ontogenic resistance to $U$. necator $\approx 3$ weeks after bloom. However, berries infected during the transition from moderate susceptibility to a high level of resistance develop the peculiar phase of the disease that we have called diffuse powdery mildew $(15,18,19)$. This phase is typified by insidious mildew colonies that are not readily visible to the naked eye in vineyard assessments (Fig. 1A), and very likely would be missed in field surveys for powdery mildew, even by experienced observers. Diffuse powdery mildew represents a colony-level reaction by the dying pathogen to the gradual development of ontogenic resistance. It involves all of the processes noted in our earlier studies of ontogenic resistance (12-15), including reduced rates of hyphal growth, increased intensity of appressorium production, death of individual hyphal segments, and the death of individual epidermal cells underlying appressoria. The end result is a wounded but macroscopically unblemished epidermis. Even under a magnification of $\times 30$, the close appression of hyphae to the highly reflective

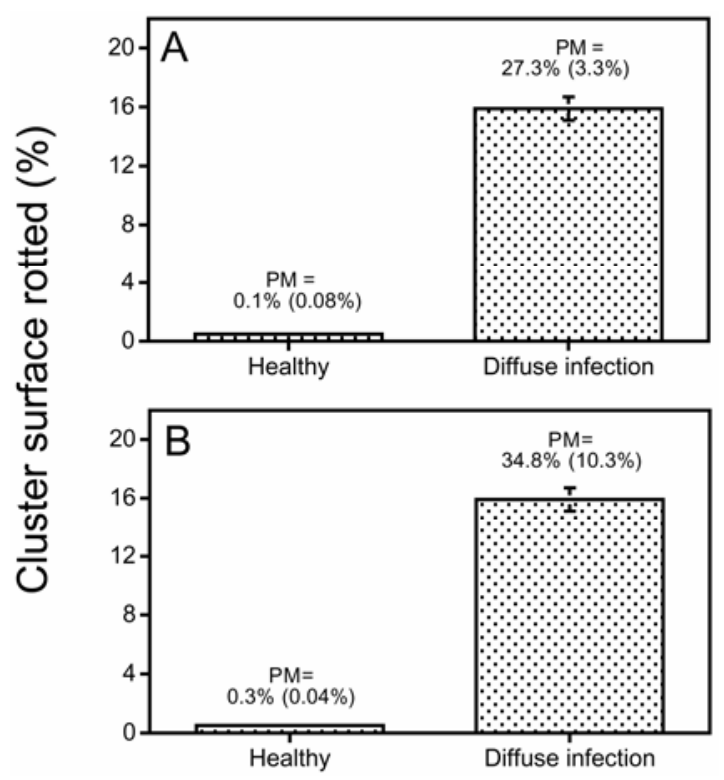

Fig. 4. Effects of diffuse powdery mildew infection of grape berries upon the severity of Botrytis bunch rot in a vineyard of Vitis vinifera 'Pinot Noir' at Lodi, NY in A, 2001 and B, 2002. All vines were subjected to the same fungicide spray program. "Healthy" clusters were relatively mildew free. "Diffuse infection" treatment was inoculated with a spore suspension of Uncinula necator midway between two fungicide sprays, just before berries became immune to powdery mildew infection ( $\approx 4$ weeks post bloom). Severity of bunch rot was assessed 1 week preharvest. Numbers above each bar indicate the percentage of berries in clusters with any amount of diffuse powdery mildew, or (in parentheses) the percentage of the berry surface covered by diffuse powdery mildew. Bars indicate one standard error of the mean. 
cuticle of the berry, the lack of sporulation, and the dehydrated condition of the dead hyphal segments that constitute much of a diffuse mildew colony make it difficult to view. However, hyphae were viewed under a dissecting microscope using oblique illumination, directing light across the mildew colony at a very shallow angle to reveal shadow details and avoid glare off the cuticular waxes (Fig, 1B).

Although the development of patches of necrotic epidermal cells (Fig. 1B and C) might provide a court for direct infection by $B$. cinerea, we lack conclusive evidence that this is the principal avenue by which diffuse powdery mildew increases the severity of Botrytis bunch rot. Sporophores of B. cinerea were observed emerging occasionally from patches of dead epidermal cells, but also from lenticels and the calyx and stem end of the fruit (Fig. 1D). Furthermore, the increased evolution of certain volatiles by fruit with diffuse infection and their associated infestation by fruit-feeding insects, accompanied by the decreased severity of bunch rot when such insects were largely excluded from fruit with diffuse powdery mildew by applications of an insecticide, suggests that a more complex process may sometimes be involved. Fruit with diffuse powdery mildew emitted increased levels of ethanol, acetic acid, and ethyl acetate before there were visible signs of rot in the cluster, and all of these volatiles are used by a number of fruit-feeding insects as sensory cues to locate sources of food $(23,24)$. At least one of the insects we found (Vespula sp.) could rapidly inflict wounds in the berry epidermis, which also might have provided an infection court for $B$. cinerea. Additionally, one or more of these insects may have physically dispersed conidia of $B$. cinerea to their feeding sites, as has been shown for larvae of the Lepidopterous insect, Lobesia botrana (11).

Fruit with diffuse powdery mildew has the potential to bring large numbers of deleterious bacteria and yeast into the grape must and, thereby, into wine fermentation. The common enological practice of adding $\mathrm{SO}_{2}$ and a Saccharomyces yeast starter culture should largely suppress the further activity of these

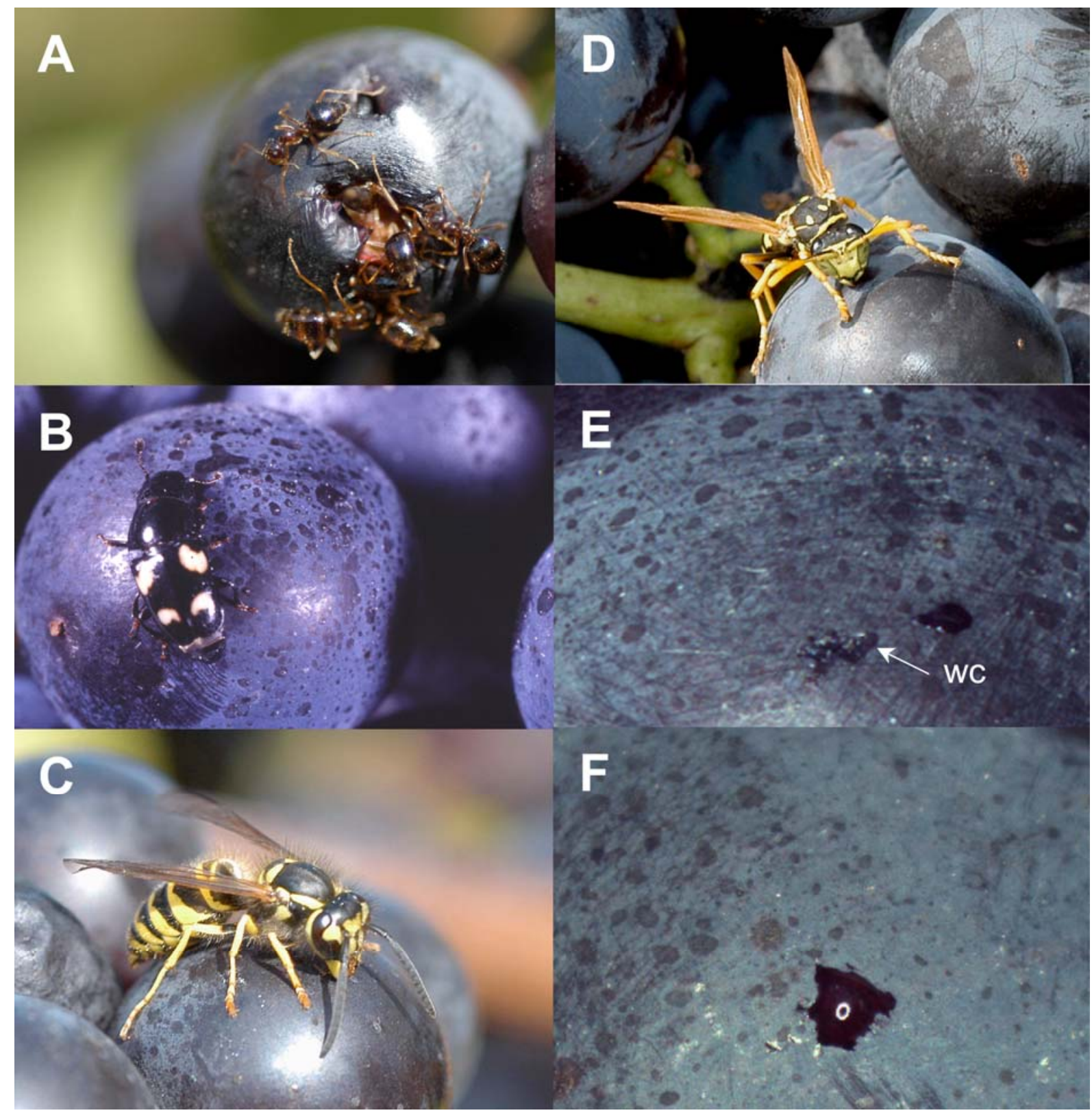

Fig. 5. Insects differentially attracted to grape berries bearing diffuse powdery colonies. A, Ants (Leptothorax sp.) congregating around cavity excavated during feeding by yellowjackets (Vesper spp.). B, Sap beetle (Glischrochilus quadrisignatus) on Pinot Noir berry. C and D, Yellowjackets preparing to feed upon berries with unbroken skin; and E, damage to Pinot Noir berry inflicted by single yellowjacket during $30 \mathrm{~s}$ of feeding. Wound cavity (wc) is $\approx 1.0 \mathrm{~mm}$ in diameter and extends through the epidermal layer into the berry pulp. F, Exudation of sap from wound cavity in Pinot Noir berry after $30 \mathrm{~s}$ of feeding by a single yellowjacket. 
numerous introduced organisms, but perhaps not before there was an impact on the sensory quality of the resulting wine. Our data indicate both a much larger overall load of non-Saccharomyces yeast and bacteria entering the winemaking process on fruit with DPM and a shift in the predominate genera from Aureobasidium on healthy fruit to Hanseniospora, Candida, and Metschnikowia on these diseased fruit. Although many of these yeast and bacteria die during the early stages of fermentation, certain genera predominating on fruit with diffuse powdery mildew (i.e., Hanseniospora and Candida) have a particularly high spoilage potential and can produce large amounts of acetic acid and acetate esters, as well as very potent and disagreeable flavors and odors that have been variously described as "fusel oil" or "cauliflower." None of the genera identified on either healthy or DPM fruit are generally recognized as risks to human health, nor was our study a comprehensive survey of the microflora of healthy or diseased fruit. Further research will be required to determine the geographic scope of the relationships we noted between diffuse powdery mildew, bunch rot, fruit-feeding insects, and wine quality. However, the general effects we observed could be widespread.

Previous studies on relationships between powdery mildew and juice or wine quality generally have focused upon (i) reduced vine function that carried over into reduced fruit quality parameters, or (ii) a direct relationship between severity of fruit disease or $U$. necator biomass and wine quality $(5,7,17,29,31,33)$. The levels of foliar powdery mildew in our study were nil; thus, the lack of any impact upon common fruit and juice quality parameters (Table 3) was not surprising. Our sensory evaluations of wines did not detect differences between wines with respect to those aspects of wine quality that primarily reflect optimal fruit maturity at harvest. Neither is the absolute quantity of $U$. necator biomass on fruit with diffuse powdery mildew comparable with that reported in studies dealing with visible and often severely diseased fruit $(7,29,31,33)$. Our results do not confirm or refute these prior studies, which dealt with quantitatively and qualitatively different forms of grape powdery mildew, but rather address a form of symptom expression and disease effects that previously were unreported. We found no single consistent or characteristic flaw in wines prepared from fruit with diffuse powdery mildew; however, the aggregate number of defects was substantially higher among such wines than in those without diffuse infection (Fig. 8). It should be noted that inconsistent and even rare defects are still of great concern in the production and marketing of fine wines and that such defects might prove economically costly should they negatively impact consumer perception of wine brands.
The insidious nature of diffuse powdery mildew has important ramifications with respect to the practical management of the disease and the design of management programs. Specifically, disease management programs are developed primarily from trials in which visual ratings of fruit in the vineyard are the principal response by which efficacy of a program is judged. Such an approach may lead to the development of programs that effectively and reliably suppress apparent disease, but provide inconsistent and unreliable suppression of diffuse powdery mildew. Although the degree to which such a risk may be realized remains unknown, our present work demonstrates several negative consequences for producing fruit that appear to be free of powdery mildew, but which harbor diffuse colonies.

Another aspect of diffuse powdery mildew relates to its exacerbation of fruit rot by $B$. cinerea. Diffuse powdery mildew could represent a confounding factor in the performance of management programs for Botrytis bunch rot and a presently unconsidered variable in Botrytis forecast models. It is interesting that the highly refined petroleum oil product, JMS Stylet Oil (JMS Flower Farms, Inc., Vero Beach, FL), has been reported in some trials on cultivars highly susceptible to powdery mildew to reduce the severity of Botrytis bunch rot (8). However, efficacy trials conducted in New York indicate that although JMS Stylet Oil is highly effective against all phases of powdery mildew, it has shown no direct efficacy against Botrytis bunch rot (35-37). This contrast raises the possibility that the observed reduction of bunch rot by the oil in some trials may occur primarily through improved control of powdery mildew on fruit, in particular the diffuse colonization phase. Thus, the control of diffuse powdery mildew may be essential to preserving the integrity of fruit clusters during a period of high risk for bunch rot.

In our experiments, diffuse powdery mildew was initiated by purposefully inoculating fruit clusters midway between two fun-

TABLE 2. Relative increase in ion peak areas for ethyl acetate, ethanol, and acetic acid yielded by Pinot Noir fruit with diffuse powdery mildew (DPM) caused by Uncinula necator relative to healthy fruit, as determined by gas chromatography and mass spectroscopy

\begin{tabular}{lccc}
\hline & \multicolumn{3}{c}{ Relative increase in ion peak area ${ }^{\mathrm{a}}$} \\
\cline { 2 - 4 } Year & Ethyl acetate & Ethanol & Acetic acid \\
\hline 2001 & 258.6 & 6.5 & $1.17 \times 10^{8}$ \\
2002 & 41.7 & 3.9 & 36.0 \\
2003 & 13.2 & 17.5 & 9.7 \\
\hline
\end{tabular}

${ }^{\text {a }}$ Ion peak area obtained for DPM fruit divided by that for healthy fruit.

TABLE 1. Effects of an insecticide on infestation of Pinot Noir grape berries by fruit-feeding insects and severity of bunch rot caused by Botrytis cinerea ${ }^{\text {a }}$

\begin{tabular}{|c|c|c|c|c|c|c|}
\hline \multirow[b]{2}{*}{ Year, category ${ }^{\mathrm{b}}$} & \multicolumn{2}{|c|}{ Powdery mildew $(\%)^{\mathrm{c}}$} & \multicolumn{2}{|c|}{ Untreated control } & \multicolumn{2}{|c|}{ Fenpropathrin treated } \\
\hline & Incidence & Severity & Infestation $(\%)^{\mathrm{d}}$ & Severity $(\%)^{\mathrm{e}}$ & Infestation $(\%)$ & Severity (\%) \\
\hline \multicolumn{7}{|l|}{2001} \\
\hline Healthy & 0.1 & 0.08 & $1.3(0.29)$ & $0.54(0.10)$ & $0.0(0)$ & $0.4(0.09)$ \\
\hline DPM & 27.3 & 3.3 & $38.3(4.33)$ & $15.9(0.52)$ & $0.0(0)$ & $5.9(1.82)$ \\
\hline \multicolumn{7}{|l|}{2002} \\
\hline Healthy & 0.3 & 0.04 & $2.7(0.49)$ & $0.8(0.11)$ & $0.0(0)$ & $0.58(0.14)$ \\
\hline DPM & 34.8 & 10.3 & $49.4(7.19)$ & $15.6(1.13)$ & $1.1(0.67)$ & $4.9(0.95)$ \\
\hline
\end{tabular}

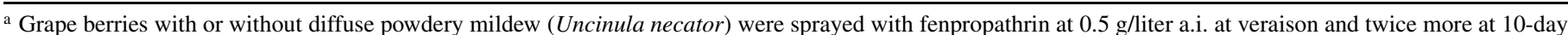
intervals in order to reduce infestation of the clusters by fruit-feeding insects. Incidence of insect infestation, incidence and severity of diffuse powdery mildew, and the severity of bunch rot was recorded at harvest in all treatments.

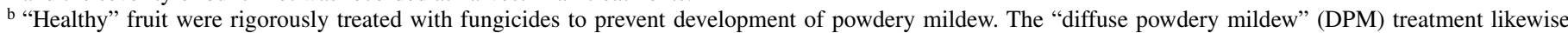
was treated with fungicides, but was inoculated with a conidial suspension of $U$. necator 3 weeks after the completion of bloom and midway between two fungicide applications.

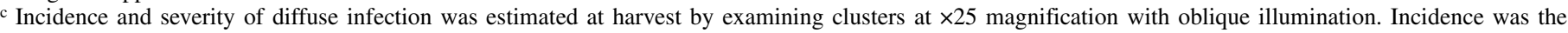
percentage of berries within a cluster that bore diffuse powdery mildew colonies. Severity was estimated from the percentage of berry surface colonized on 10 berries per sampled cluster.

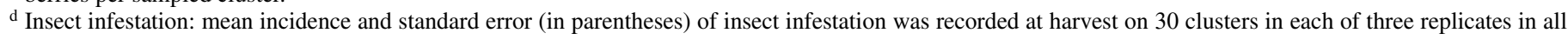
treatments.

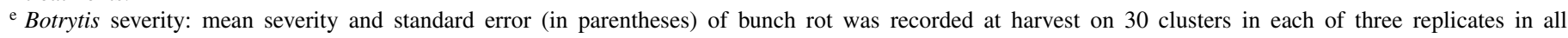
treatments. 
gicide applications at a specific stage of crop development (i.e., $\approx 3$ weeks after bloom). In a more natural setting, diffuse powdery mildew might become established through two principle avenues: first, if fungicidal protection lapses for any reason immediately before the fruit acquire a high level of ontogenic resistance at 3 to 4 weeks post bloom; and, second, growth of earlier-established colonies on the fruit might be halted temporarily by the fungi-
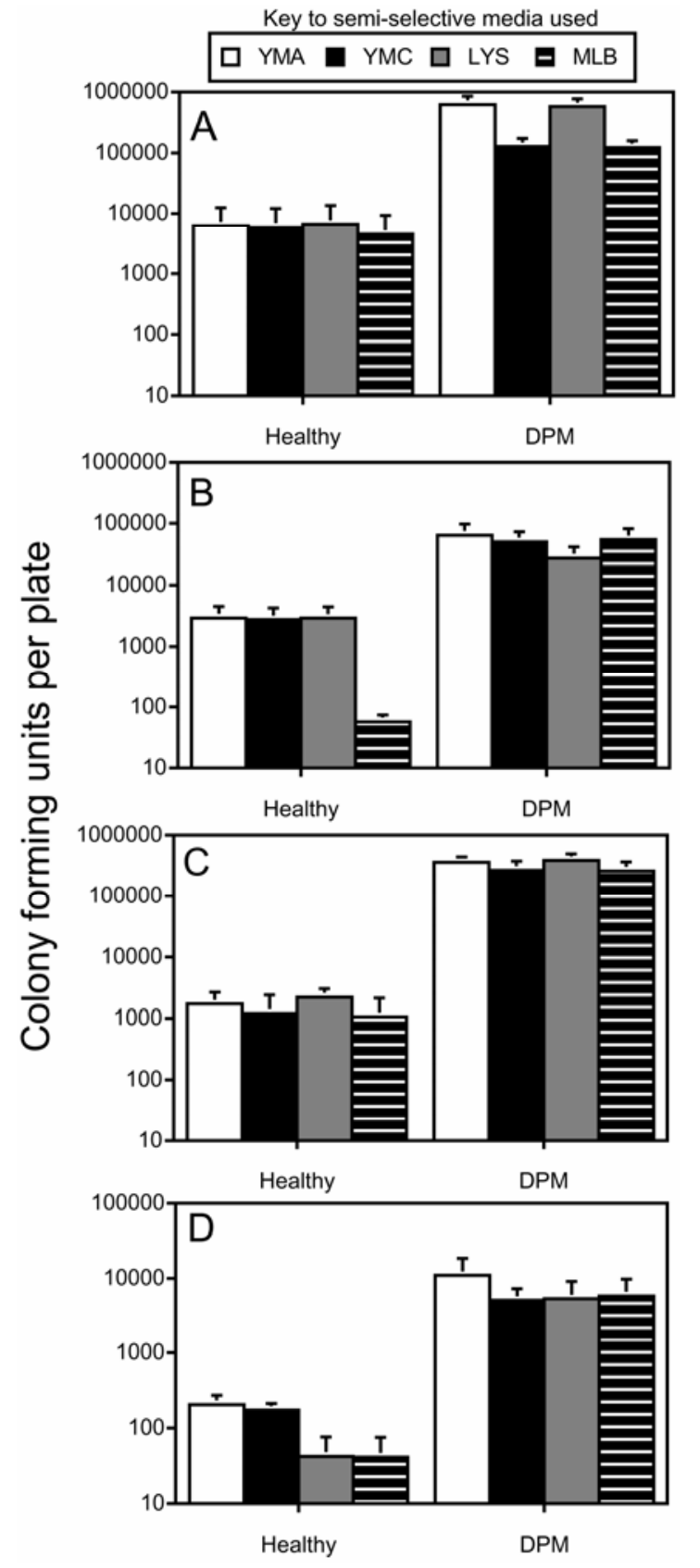

Fig. 6. Microflora associated with powdery mildew-free berries of Vitis vinifera 'Pinot Noir' (Healthy) versus those supporting diffuse powdery mildew colonies (DPM) in A, Geneva or B, Lodi in 2000 and in Lodi in C, 2001 and D, 2002. Within years at each site, vines were subjected to the same fungicide spray program, but clusters in the DPM treatment were inoculated with conidia of Uncinula necator midway between two fungicide sprays just before berries became immune to powdery mildew infection $(\approx 3$ weeks post bloom). Fruit were harvested ripe, and three replicate lots of 100 berries per treatment were washed and the rinsate plated on four semiselective agar media. Heights of bar segments indicate the total number of CFU per 100- $\mu 1$ sample of the following microorganisms per medium: YMA (yeast medium agar) $=$ all yeasts; YMC (YMA plus cycloheximide) = Brettanomyces and Dekkera yeasts; LYS (lysine agar medium) $=$ non-Saccharomyces yeasts, presumably Kloeckera; and MLB (malolactic broth agar with cycloheximide) = lactic acid bacteria. Error bars indicate one standard error of the mean. static action of demethylation inhibiting (DMI) fungicides, but then resume before fruit acquire sufficient ontogenic resistance. A related phenomenon has been demonstrated with respect to fungistatic effects of DMI fungicides applied to apple foliage and survival of Venturia inaequalis $(4,10,28)$, and potentially could be of more concern where efficacy of DMI fungicides has eroded due to population shifts toward decreased fungicide sensitivity $(9,22)$. Diffuse powdery mildew can be prevented if effective protection of fruit is extended to include that period during which fruit are susceptible only to diffuse powdery mildew (15). Although this slightly more intensive use of fungicides might not be accompanied by a macroscopically visible reduction of powdery mildew on the fruit, our previous studies $(12,15)$ have demonstrated that doing so effectively prevents diffuse powdery mildew and the attendant problems associated with this phase of the disease. The precise delimitation of the period of berry susceptibility is somewhat dependent upon climate (i.e., the period of bloom becomes longer and the period of berry development and, consequently, that of ontogenic resistance development becomes more heterogeneous within a fruit cluster as winter temperatures increase) $(20,21)$. This climate-dependent phenological heterogeneity is a common phenomenon in many deciduous tree fruit, but has received little attention as it relates to the distribution of ontogenic resistance and consequent risk of disease. This is especially relevant to the findings reported herein because, as grapevine bloom becomes more heterogeneous with less winter chilling, so would the potential increase for development of diffuse powdery mildew. Part of our continuing research seeks to better define how climate affects grapevine flowering and, thereby, the period during which fruit are susceptible to powdery mildew and other fungal diseases $(20,21)$.

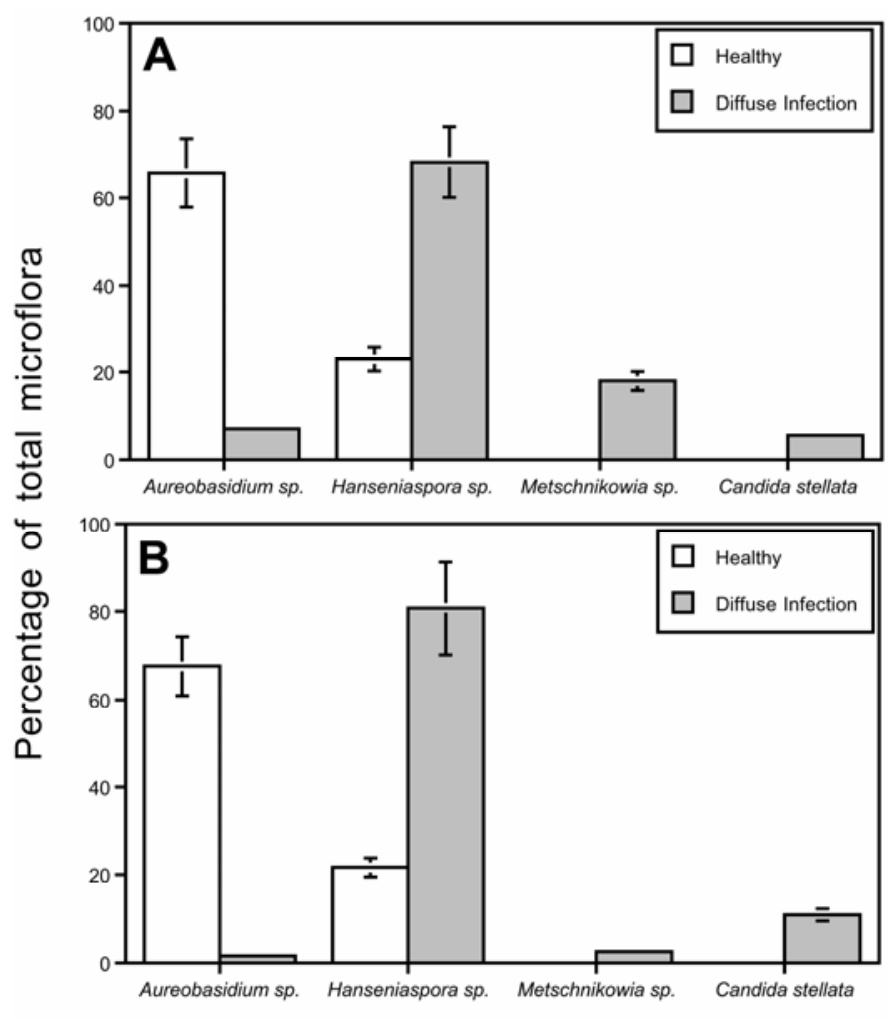

Genera

Fig. 7. Composition of epiphytic yeasts isolated from healthy and diffuse powdery mildew (Diffuse infection) berries in A, 2001 and $\mathbf{B}, 2002$ identified by polymerase chain reaction sequencing methods. Twenty colonies selected arbitrarily from each of three replicate culture plates of lysine medium were subcultured and subsequently identified, and the percentages of the total microflora for each identified genus was calculated. Bars indicate one standard error of the mean. 
TABLE 3. Effects of diffuse powdery mildew (DPM) caused by Uncinula necator on juice and wine quality from Pinot Noir grape berries

\begin{tabular}{|c|c|c|c|c|c|c|c|}
\hline Year, treatment ${ }^{\mathrm{a}}$ & $\mathrm{PH}^{\mathrm{b}}$ & Soluble solids $(\%)^{\mathrm{c}}$ & Titratable acids $(\mathrm{g} / \text { liter })^{\mathrm{d}}$ & Tartrate $(\mathrm{g} / \text { liter })^{\mathrm{e}}$ & Malate (g/liter) ${ }^{\mathrm{e}}$ & Lactate $(\mathrm{g} / \text { liter })^{\mathrm{e}}$ & Acetate $(\mathrm{g} / \mathrm{liter})^{\mathrm{e}}$ \\
\hline \multicolumn{8}{|l|}{2000} \\
\hline Without DPM & 3.60 & 20.6 & 6.15 & 0.87 & 0.17 & 2.94 & 0.42 \\
\hline With DPM & 3.57 & 20.3 & 6.05 & 0.94 & 0.22 & 2.69 & 0.46 \\
\hline \multicolumn{8}{|l|}{2001} \\
\hline Without DPM & 4.04 & 22.4 & 5.07 & 2.79 & $>0.10$ & 5.10 & 0.63 \\
\hline With DPM & 3.88 & 22.7 & 5.43 & 2.89 & $>0.10$ & 4.73 & 0.62 \\
\hline \multicolumn{8}{|l|}{2002} \\
\hline Without DPM & 3.77 & 19.3 & 5.43 & 0.83 & 0.13 & 3.01 & 0.39 \\
\hline With DPM & 3.77 & 18.9 & 5.43 & 0.74 & 0.19 & 2.90 & 0.37 \\
\hline
\end{tabular}

${ }^{a}$ Grape berries without DPM were protected from infection by an intensive fungicide program. Berries with DPM were protected by the same fungicide program, but were inoculated with a suspension containing $U$. necator at $10^{5}$ conidia/ml midway between two fungicide applications, $\approx 3$ weeks post-bloom, and developed disease on at least $25 \%$ of all berries by the time of harvest.

${ }^{\mathrm{b}} \mathrm{pH}$ of wine after malolactic fermentation, before adjustment of titratable acids. Within-year differences are not significant at $P=0.05$ according to Student's $t$ test.

c Soluble solids (primarily sugars) in fresh juice at the time of harvest.

d Titratable acid level of wine after malolactic fermentation, before adjustments of acidity.

e Tartrate, malate, lactate, or acetate levels in wine after malolactic fermentation, before adjustment of titratable acids.

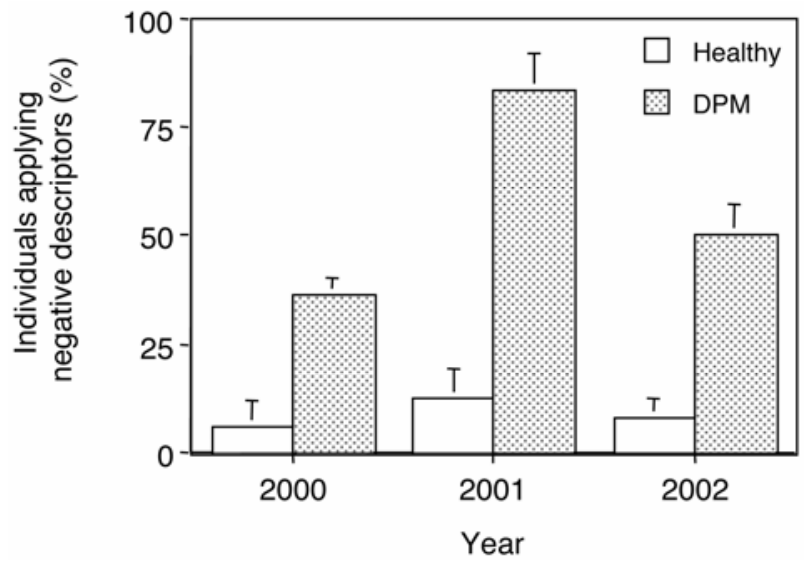

Fig. 8. Percentage of individuals that applied one or more negative descriptors to wines prepared from Pinot Noir grape berries harvested in 2000, 2001, or 2002 that bore trace levels (incidence $=1$ to $4 \%$ ) of diffuse powdery mildew (Healthy) versus berries bearing numerous (incidence $=27$ to $58 \%$ ) diffuse powdery mildew colonies (DPM). Wines were evaluated 18 months after bottling by 8 to 11 experienced tasters in a double-blind comparison in which each of three replicates per treatment was sampled twice. Negative descriptors of taste or odor that were perceived by an individual in both the first and second sampling of a replicate were compiled and the percentage of individuals on a panel that applied one or more negative attributes to a replicate was recorded. Negative descriptors were: "bretty, adhesive tape, spoiled fruit, Band-aid, manure, barnyard, mousy, burlap, rotted vegetables, musty, dirty, pondwater, algal, stinky, spoilage, sweaty, burnt plastic, aldehyde, urine, bitter, off-aroma, oxidized, unpleasant, and foul." Bars indicate one standard error of the mean.

\section{ACKNOWLEDGMENTS}

This research was generously supported by the United States Department of Agriculture (USDA) FAS/OICD/RSED competitive grants program, by the USDA Viticulture Consortium (East) competitive grants program, the New York Wine and Grape Foundation, The New York Grape Production Research Fund, The Lake Erie Regional Grape Program, and the Kaplan Fund. We thank E. Lavin (Cornell University) for excellent technical assistance in the GCMS analysis of fruit volatiles; the many volunteers who suffered through 3 years of tasting several foul wines; the late R. Pool (Cornell University), who donated the crop from one of his research vineyards in the first year of our study; D. Riegel and S. Lerch (both of Cornell University) for their invaluable assistance in maintaining the experimental vineyards; and M. Wagner, owner of Lamoreaux Landing Wine Cellars (Lodi, NY), who graciously sacrificed several tons of his Pinot Noir crop to our research over the course of the study.

\section{LITERATURE CITED}

1. Amati, A., Piva, A., Castellari, M., and Arfelli, G. 1996. Preliminary studies on the effect of Oidium tuckeri on the phenolic composition of grapes and wines. Vitis 35:149-150.

2. Anonymous. 2006. Difco Manual of Dehydrated Culture Media and Reagents for Microbiological and Clinical Laboratory Procedures. Difco Laboratories, Detroit.

3. Barnett, J. A., Payne, R. W., and Yarrow, D. 1990. Yeasts: Characteristics and Identification. Cambridge University Press.

4. Berton, O., Gadoury, D. M., Seem, R. C., and Wilcox, W. F. 1998. Ontogenic resistance to apple scab, post-infection use of fenarimol, and the distribution of symptom expression. (Abstr.) Phytopathology 89:S6.

5. Calonnec, A., Cartolaro, P., Poupot, C., Dubourdieu, D., and Darriet, P. 2004. Effects of Uncinula necator on the yield and quality of grapes (Vitis vinifera) and wine. Plant Pathol. 53:434-445.

6. Cox, D. J., and Henick-Kling, T. 1995. Protonmotive force and ATP generation during malolactic fermentation. Am. J. Enol. Vitic. 46:319323.

7. Darriet, P., Pons, M., Henry, R., Dumont, O., Findling, V., Cartolaro, P., Calonnec, A., and Dubourdieu, D. 2002. Impact odorants contributing to the fungus type aroma from grape berries contaminated by powdery mildew (Uncinula necator)-incidence of enzymatic activities of the yeast Saccharomyces cerevisiae. J. Agric. Food Chem. 50:3277-3282.

8. Dell, K. J., Gubler, W. D., Krueger, R., Sanger, M., and Bettiga, L. J. 1998. The efficacy of JMS Stylet-Oil on grape powdery mildew and Botrytis bunch rot and effects on fermentation. Am. J. Enol. Vitic. 49:1116.

9. Erickson, E. O., and Wilcox, W. F. 1997. Distribution of sensitivities to three sterol demethylation inhibitor fungicides among populations of Uncinula necator sensitive and resistant to triadimefon. Phytopathology 87:784-791.

10. Falk, S. P., Gadoury, D. M., and Seem, R. C. 1996. Impact of fenarimol on symptom expression and survival of stromata of Venturia inaequalis. (Abstr.) Phytopathology 86(suppl.):S121.

11. Fermaud, M., and Le Menn, R. 1989. Association of Botrytis cinerea with grape berry moth larvae. Phytopathology 79:651-656.

12. Ficke, A., Gadoury, D. M., Seem, R. C., and Dry, I. B. 2003. Effects of ontogenic resistance upon establishment and growth of Uncinula necator on grape berries. Phytopathology 93:556-563.

13. Ficke, A., Gadoury, D. M., Seem, R. C., Godfrey, D., and Dry, I. B. 2004. Host barriers and responses to Uncinula necator in developing grape berries. Phytopathology 94:438-445.

14. Gadoury, D. M., Seem, R. C., Ficke, A., and Wilcox, W. F. 2001. The epidemiology of powdery mildew on Concord grapes. Phytopathology 91:948-955.

15. Gadoury, D. M., Seem, R. C., Ficke, A., and Wilcox, W. F. 2003. Ontogenic resistance to powdery mildew in grape berries. Phytopathology 93:547-555.

16. Gadoury, D. M., Seem, R. C., Ficke, A. Wilcox, W. F., and Henick-Kling, T. 2000. Diffuse infections of Uncinula necator predispose grape berries to bunch rot and spoilage microorganisms, and degrades wine quality. (Abstr.) Phytopathology 90(suppl.):S26.

17. Gadoury, D. M., Seem, R. C., Pearson, R. C., Wilcox, W. F., and Dunst, R. M. 2001. Effects of powdery mildew on vine growth, yield, and quality of Concord grapes. Plant Dis. 85:137-140. 
18. Gadoury, D. M., Seem, R. C., Wilcox, W. F., Conterno, L., and HenickKling, T. 2002. Effetto dell'infezione oidica sulla qualitá del mosto e del vino. Inf. Fitopatol. 4:28-32.

19. Gadoury, D. M., Seem, R.C., Wilcox, W. F., and Henick-Kling, T. 2002. Effects of powdery mildew on bunch rots, berry microflora, and juice and wine quality. Pages 64-65 in: Proc. 4th Int. Workshop Grapevine Downy and Powdery Mildew. University of California-Davis Press, Davis.

20. Gadoury, D. M., Seem, R. C., Wilcox, W. F., and Kennelly, M. M. 2005. Climate-based modeling of ontogenic resistance to major fungal diseases of grapevine. (Abstr.) Phytopathology 95:S33.

21. Gadoury, D. M., Seem, R. C., Wilcox, W. F., Kennelly, M. M., Magarey, P. A., Dry, I. B., Gubler, D., Pscheidt, J. W., Grove, G., Sutton, T. B., Ellis, M. A., Stevenson, K. L., Maixner, M., and Evans, K. J. 2006. Modeling and mapping the relationship between climate and ontogenic resistance to the major fungal diseases of grapevine. Pages 157-159 in: Proc. 5th Int. Workshop Grapevine Downy and Powdery Mildew. I. Pertot, C. Gessler, D. M. Gadoury, D. Gubler, H. H. Kassemeyer, and P. Magarey, eds. Istituto Agrario di San Michele all'Adige.

22. Gubler, W. D., Ypema, H. L., Ouimette, D. G., and Bettiga, L. J. 1996. Occurrence of resistance in Uncinula necator to triadimefon, myclobutanil, and fenarimol in California grapevines. Plant Dis. 80:902-909.

23. Hsiao, T. H. 1985. Feeding behavior. In: Comprehensive Insect Physiology, Biochemistry, and Pharmacology, vol. 9. G. A. Kerkut and L. I. Gilbert, eds. Pergamon Press, Oxford.

24. Jander, R. 1988. Olfactory learning of fruit odors in the eastern yellow jacket, Vespula maculifrons (Hymenoptera: Vespidae). J. Insect Behav. 11:879-888.

25. Kurtzman, C. P., and Robnett, C. J. 1998. Identification and phylogeny of ascomycetous yeasts from analysis of nuclear large subunit (26S) ribosomal DNA partial sequences. Antonie Leeuwenhoek 73:331-371.

26. Lawless, H. T., and Heymann, H. 1997. Pages 217-220 in: Sensory Evaluation of Food: Principles and Practices. Chapman \& Hall, New York.
27. O’Donnell, K. 1993. Fusarium and its near relatives. Pages 225-233 in: The Fungal Holomorph: Mitotic, Meiotic and Pleomorphic Speciation in Fungal Systematics. D. R. Reynolds and J. W. Taylor, eds. CAB International, Wallingford, UK.

28. O'Leary, A. L., Jones, A. L., and Ehret, G. R. 1987. Application rates and spray intervals for apple scab control with flusilazol and pyrifenox. Plant Dis. 71:623-626.

29. Ough, C. S., and Berg, H. W. 1979. Powdery mildew sensory effect on wine. Am. J. Enol. Vitic. 30:321-326.

30. Pawliszyn, J. 1997. Solid Phase Microextraction: Theory and Practice. Wiley-VCH, New York.

31. Pool, R. M., Pearson, R. C., Welser, M. J., Lakso, A. N., and Seem, R. C. 1984. Influence of powdery mildew on yield and growth of Rosette grapevines. Plant Dis. 68:590-593.

32. Sambrook, J., Fritsch, E. F., and Maniatis, T. 1989. Molecular Cloning: A Laboratory Manual, 2nd ed. Cold Spring Harbor Laboratory, Cold Spring Harbor, NY.

33. Stummer, B. E., Francis, I. L., Zanker, T., Lattey, K. A., and Scott, E. S. 2005. Effects of powdery mildew on the sensory properties and composition of Chardonnay juice and wine when grape sugar ripeness is standardized. Aust. J. Grape Wine Res. 11:66-76.

34. Walters, L. S., and Thiselton, M. R. 1953. Utilisation of lysine by yeasts. J. Inst. Brew. 59:401-404.

35. Wilcox, W. F., and Riegel, D. G. 1996. Evaluations of fungicides and spray timings for control of Botrytis bunch rot of grapes, 1995. Fungic. Nematicide Tests 51:73.

36. Wilcox, W. F., and Riegel, D. G. 1997. Evaluations of fungicide programs for control of Botrytis bunch rot of grapes, 1996. Fungic. Nematicide Tests 52:86.

37. Wilcox, W. F., and Riegel, D. G. 1998. Evaluations of fungicide programs for control of Botrytis bunch rot of grapes, 1997. Fungic. Nematicide Tests 53:104. 